\title{
Sustained response after a 2-year course of lamivudine treatment of hepatitis $B$ e antigen-negative chronic hepatitis $B$
}

\author{
S. K. Fung, ${ }^{1,2}$ F. Wong, ${ }^{1}$ M. Hussain ${ }^{2}$ and A. S. F. Lok ${ }^{2}{ }^{1}$ Department of Medicine, University of Toronto, Toronto, Ont., \\ Canada; and ${ }^{2}$ Division of Gastroenterology, University of Michigan, Ann Arbor, MI, USA
}

Received October 2003; accepted for publication November 2003

SUMMARY. Lamivudine has demonstrated efficacy for the treatment of hepatitis $\mathrm{B}$ e antigen-negative chronic hepatitis $\mathrm{B}$ (e-CHB). However, treatment withdrawal after 1 year has been associated with a high rate of relapse while long-term treatment is associated with increasing risks of drug resistance. We report our treatment experience of 50 ChineseCanadian patients with e-CHB. All patients received lamivudine for 2 years. Treatment was withdrawn at month 24 in patients who had undetectable hepatitis B virus (HBV) DNA by PCR and normal aminotransferases during the second year of therapy. All patients had HBV genotype B or C. Biochemical response at months 6,12 and 24 was $74 \%$, $71 \%$ and $66 \%$, respectively. HBV DNA was undetectable at months 6,12 and 24 by hybrid capture and PCR assays in
$100 \%, 92 \%$ and $86 \%$; and $94 \%, 88 \%$ and $74 \%$ patients, respectively. The cumulative rates of genotypic resistance (GR) after 1 and 2 years were $15 \%$ and $25 \%$, respectively. Four $(44 \%)$ patients with GR experienced a hepatitis flare. The probability of clinical and virological relapse 6,12 , and 18 months after treatment withdrawal were $12 \%$ and $30 \%$, $18 \%$ and $50 \%$, and $30 \%$ and $50 \%$, respectively. Reinstitution of lamivudine resulted in prompt virological and biochemical responses. Our study demonstrates that a sustained response can be achieved after a 2-year course of lamivudine in a subset of patients with e-CHB.

Keywords: HBV core promoter mutation, HBV precore mutation, hepatitis B virus genotypes, lamivudine resistance.

\section{INTRODUCTION}

Hepatitis B e antigen-negative chronic hepatitis B (e-CHB) is characterized by the absence of hepatitis $\mathrm{B}$ e antigen (HBeAg), detectable serum hepatitis B virus (HBV) DNA by non-PCR-based assays, and liver necroinflammation (abnormal aminotransferases, histological evidence of chronic hepatitis with/without cirrhosis) [1]. This condition has been reported worldwide but is most commonly seen in Mediterranean countries, the Middle East and East Asia [2-9]. In a recent report from Hong Kong, over 20\% of patients with chronic $\mathrm{HBV}$ infection seen in a university teaching hospital hepatitis clinic were found to have e-CHB [10]. Most patients with e-CHB harbour variants of HBV that contain mutations in the precore or core promoter regions of the $\mathrm{HBV}$ genome that abolish or down-regulate

Abbreviations:ALT, alanine aminotransferase; anti-HBe, HBe antibody; e-CHB, hepatitis B e antigen-negative chronic hepatitis B; GR, genotypic resistance; $\mathrm{HBeAg}$, hepatitis $\mathrm{B}$ e antigen; $\mathrm{HBsAg}$, hepatitis B surface antigen; HBV, hepatitis B virus; ULN, upper limit of normal.

Correspondence: Dr Scott K. Fung, Division of Gastroenterology, University of Michigan Medical Center, 4321 Med Sci 1, Box 0601, Ann Arbor, MI 48109-0601, USA. E-mail: scofung@med.umich.edu the production of HBeAg. The precore stop codon mutation $\left(\mathrm{G}_{1896} \mathrm{~A}\right)$ has been found in over $90 \%$ of Europeans but only in $<50 \%$ of Chinese patients with e-CHB $[2,3,10]$. The prevalence of the dual mutation $\left(\mathrm{A}_{1762} \mathrm{~T}+\mathrm{G}_{1764} \mathrm{~A}\right)$ in the core promoter region among patients with e-CHB is less clear [11]. The vast majority of European patients with e-CHB are infected with HBV genotype D but most Asian patients with e-CHB are infected with HBV genotypes $\mathrm{B}$ and C $[12,13]$.

Lamivudine is effective in the treatment of HBeAg-positive as well as HBeAg-negative chronic hepatitis B [14-20]. Several studies of patients with e-CHB have reported response rates, defined as undetectable HBV DNA by solution hybridization or branched DNA assays and normal alanine aminotransferase (ALT), of $60-70 \%$ at the end of 1 year of lamivudine treatment [16-20]. However, withdrawal of lamivudine therapy is associated with a relapse rate of approximately $90 \%$ within 6 months of treatment discontinuation (abnormal ALT and re-detection of serum HBV DNA using non-PCR-based assays) when lamivudine was given for only 1 year [16,21]. In attempts to increase the sustained response rates, many investigators have explored extended or indefinite lamivudine treatment for patients with e-CHB. However, long-term therapy is associated with increasing rates of virological breakthrough, from 10-30\% 
at 1 year $[15,18,19,22,23]$ to $50 \%$ at 2 years $[22,24]$ because of selection of mutations in the YMDD motif of the HBV DNA polymerase gene (rtM204V/I \pm rtL180M). A recent study suggested that all patients with virological breakthrough developed biochemical relapse within 24 months [24]. These data indicate that the initial benefit of lamivudine treatment may ultimately be negated in patients who developed lamivudine resistance. Thus, it is important to determine if sustained off-treatment response can be achieved after a 2-year course of therapy.

We report our experience with lamivudine treatment in Chinese adults with e-CHB. The aims of this analysis were to determine: (i) the virological and biochemical response to a 2-year course of lamivudine treatment in Chinese adults with e-CHB; (ii) the rate of virological and biochemical breakthrough during lamivudine therapy; and (iii) the durability of the response to lamivudine following withdrawal of therapy in patients who have not developed lamivudine resistance after 2 years of treatment.

\section{METHODS}

\section{Patients}

Consecutive Chinese adult patients with e-CHB treated with lamivudine at the Hepatology Clinic of the Toronto General Hospital between January 1999 and December 2001 were reviewed. Only patients who met the following criteria were included: hepatitis B surface antigen ( $\mathrm{HBsAg}$ ) positive, $\mathrm{HBeAg}$ negative, HBe antibody (anti-HBe) positive, detectable serum HBV DNA by hybrid capture assay, and alanine aminotransferase (ALT) $>1.5 \times$ upper limit of normal (ULN, $40 \mathrm{IU} / \mathrm{L}$ ), on two separate occasions during the 6-month period prior to the start of therapy. Patients were excluded if they were coinfected with hepatitis $\mathrm{C}$ virus (HCV), hepatitis D virus (HDV) and/or human immunodeficiency virus (HIV). All patients underwent a liver biopsy prior to starting lamivudine therapy as per the usual practice at the institution. Inflammation and fibrosis were separately graded on a scale of 0-4 [25]. All patients who received lamivudine therapy for e-CHB during the study period met eligibility criteria and were included in this analysis.

\section{Definitions}

Virological response was defined as undetectable serum HBV DNA by PCR assay. Biochemical response was defined as decrease of ALT to normal range. Genotypic resistance (GR) was defined as detection of rtM204V/I mutation. Virological breakthrough was defined as reappearance of HBV DNA by PCR during treatment after initial disappearance using PCR assay. Biochemical breakthrough was defined as abnormal ALT during treatment after initial normalization. Virological relapse after treatment withdrawal was defined as reappearance of HBV DNA by PCR assay. Clinical relapse after treatment withdrawal was defined as detection of HBV DNA by hybrid capture assay and ALT >1.5 × ULN.

\section{Treatment protocol}

All patients received lamivudine $100 \mathrm{mg}$ orally daily. All patients were evaluated at monthly intervals for 3 months and thereafter at 3-monthly intervals. At each visit, patients were screened for medication side-effects and tests for liver chemistries, complete blood count, prothrombin time (INR: international normalized ratio) hepatitis B serology and HBV DNA were performed. In addition, extra sera were collected at each visit and subsequently retrieved for HBV DNA testing by PCR assay and for the detection of lamivudine resistance mutations. Pretreatment samples were also tested for HBV genotype. Serial samples prior to treatment and every 3-6 months thereafter were tested for precore, core promoter and polymerase gene mutations.

Treatment was withdrawn in patients who had undetectable HBV DNA by PCR and normal ALT on at least three consecutive occasions during the second year of therapy and at month 24. These patients were monitored monthly for 3 months, 3-monthly for the remainder of the year, and thereafter every 6 months. Patients who had clinical relapse after treatment withdrawal were restarted on lamivudine $100 \mathrm{mg}$ orally daily.

\section{$H B V$ assays}

Serum HBV DNA levels were determined using the Digene Hybrid Capture II assay (Digene Corporation, Gaithersburg, $\mathrm{MD}$, USA) which has a lower limit of detection of $1.4 \times 10^{5}$ copies $/ \mathrm{mL}$ or $0.5 \mathrm{pg} / \mathrm{mL}$ as well as the Cobas Amplicor HBV Monitor assay (Roche Molecular Diagnostics, Chatsworth, CA, USA) which has a lower limit of detection of 200 copies/mL [26]. HBV genotype, precore and core promoter mutations as well as lamivudine-resistant HBV polymerase gene mutations were detected by PCR and direct sequencing [22].

\section{Statistical analyses}

Results were expressed either as mean \pm standard deviation or median and range. A database was created using Excel (Microsoft, Redmond, WA, USA) and analysed using the SPSS statistics program (SPSS Inc, Chicago, IL, USA). Statistical analyses were performed using chi-square and Fisher's exact test for categorical variables. The student's $t$-tests were used for continuous variables. Rates of GR, virological relapse and clinical relapse were estimated using the KaplanMeier method. Results were considered statistically significant at $P<0.05$. 


\section{RESULTS}

\section{Baseline demographic and virological data}

Baseline demographic, clinical and virological data are shown in Table 1. Data on 50 patients who have completed at least 1 year of therapy are included in this report. Of these, $37(74 \%)$ patients have completed 2 years of therapy; while the remaining 13 patients were receiving the second year of treatment. All patients were ethnically Chinese, the mean age was $45.1 \pm 10.3$ years, and 40 $(80 \%)$ were men. Fourteen $(28 \%)$ patients had evidence of cirrhosis on biopsy. The median pretreatment ALT was $93 \mathrm{IU} / \mathrm{L}$. The median HBV DNA level was $1.1 \times 10^{7}$ copies $/ \mathrm{mL}$. All patients had HBV genotype C $(78 \%)$ or B $(22 \%)$, none had genotype D. Precore stop codon mutation with or without core promoter mutation was found in 27 (54\%) patients. None of the patients had previously received interferon or other antiviral therapy for chronic hepatitis B. The mean duration of continuous lamivudine therapy was $32.6 \pm 13.0$ months, as some of the patients who developed GR were continued on treatment beyond 24 months.

\section{Biochemical response}

The percentage of patients with biochemical response at different time points is illustrated in Fig. 1. Normalization of ALT was observed in $74 \%$ patients at month 6 but decreased to $71 \%$ at month 12 and $66 \%$ at month 24 .

Table 1 Baseline characteristics of patients

\begin{tabular}{ll}
\hline No. of patients & 50 \\
Gender M:F & $40: 10$ \\
Mean age (years) \pm SD & $45.1 \pm 10.3$ \\
Median ALT/ULN (range) & $2.3(0.8-24.9)$ \\
Patients with ALT >5 $\times$ ULN (\%) & $9(18)$ \\
Median (range) HBV DNA in & $7.0(6.2-8.8)$ \\
$\log _{10}$ copies/mL (Digene) & \\
Liver histology & \\
$\quad$ No. (\%) of patients with cirrhosis & $14(28)$ \\
$\quad$ Median (range) inflammatory & $2(1-3)$ \\
$\quad$ score (max = 4) & $3(1-4)$ \\
Median (range) fibrosis score (max $=4)$ & \\
HBV genotype - no. (\%) & $11(22)$ \\
$\quad$ Genotype B & $39(78)$ \\
$\quad$ Genotype C & $8(16)$ \\
Precore/core promoter variant - no. $(\%)$ & \\
$\quad$ Precore variant only & $21(42)$ \\
$\quad$ Core promoter variant only & $2(38)$ \\
Precore and core promoter mutations & $19(4)$ \\
$\quad$ Wild-type sequence & \\
\hline
\end{tabular}

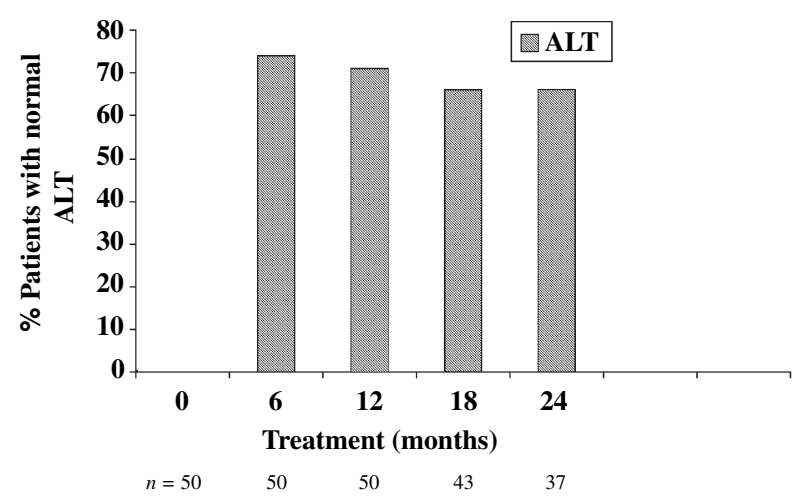

Fig. 1 Percentage of patients with biochemical response at various time-points during the first 2 years of treatment Biochemical response was defined as a decrease of ALT to normal range (ULN, $40 \mathrm{IU} / \mathrm{L}$ ).

\section{Virological response}

The percentage of patients with undetectable serum HBV DNA using hybrid capture and PCR assays is shown in Fig. 2. At month 6, HBV DNA became undetectable using hybrid capture assay in all patients and in all but three patients (94\%) using PCR assay. With the emergence of lamivudine-resistant mutations, the percentage of patients with virological response declined. HBV DNA remained undetectable at months 12,18 and 24 using hybrid capture and PCR assays in $92 \%$ and $88 \%, 90 \%$ and $78 \%, 86 \%$ and $74 \%$ patients, respectively. No patient lost HBsAg during the study.

\section{Genotypic resistance}

Genotypic resistance to lamivudine was detected in nine patients (18\%) before month 24 of treatment, with a mean

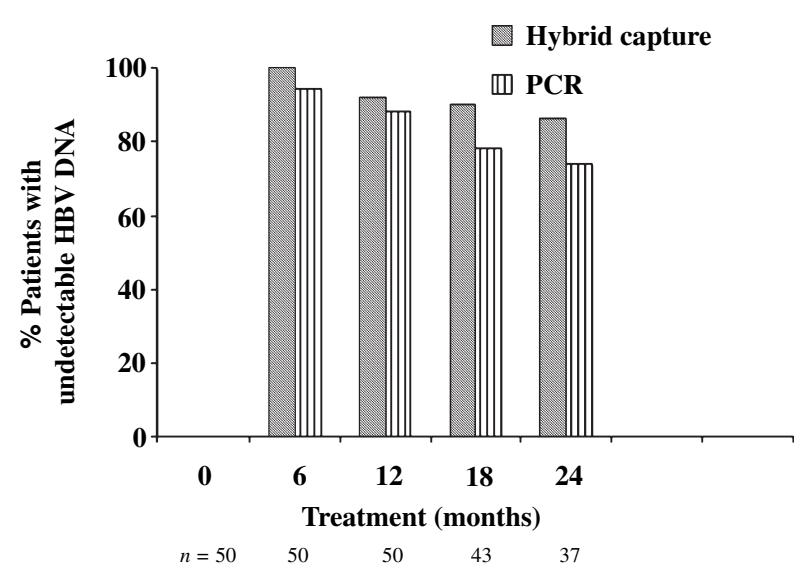

Fig. 2 Percentage of patients with virological response at various time-points during the first 2 years of treatment Virological response as determined by undetectable serum HBV DNA using hybrid capture $(<5 \mathrm{pg} / \mathrm{mL})$ and PCR assays $(<200$ copies/mL). 


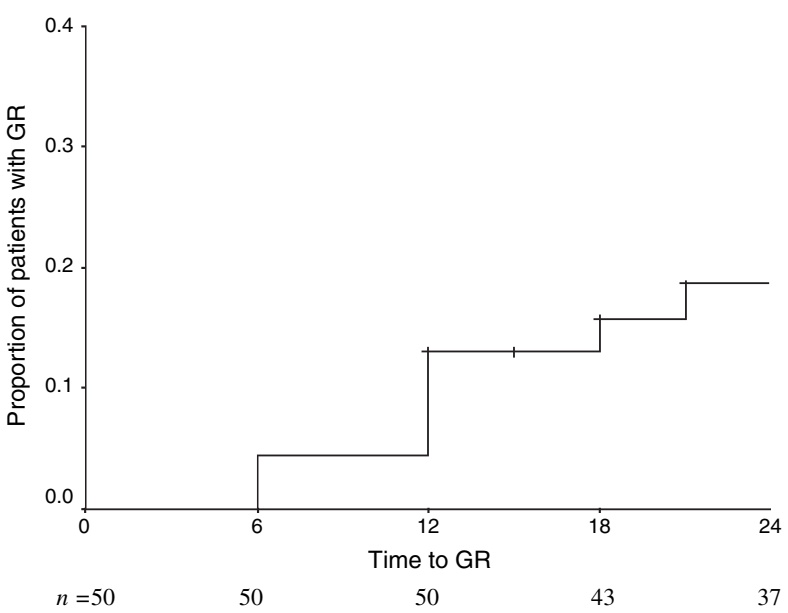

Fig. 3 Cumulative rates of genotypic resistance (GR) during the first 2 years of treatment GR was defined as detection of rtM204V/I mutation.

time to detection of $13.7 \pm 6.2$ months. The cumulative rates of GR at months 12 and 24 were $15 \%$ and $25 \%$, respectively (see Fig. 3). Three patients had a combination of rtL180M and rtM204V mutations, two had a combination of rtL180M and rtM204I mutations, while four had an isolated rtM204I mutation. There was no difference in age, gender, pretreatment ALT, HBV DNA, liver histology, HBV genotype, precore or core promoter sequence between the patients with and without GR.

The nine patients with GR remained on lamivudine treatment for $20.1 \pm 11.0$ months after the first detection of lamivudine-resistant mutations. All patients had detectable HBV DNA by PCR, six (67\%) patients also had detectable serum HBV DNA by hybrid capture assay. Biochemical breakthrough occurred in seven $(78 \%)$ patients. Four patients $(44 \%)$ had ALT flares $>5 \times$ ULN, two patients $(22 \%)$ also had an increase in bilirubin level. One (11\%) patient developed hepatic decompensation with ascites 12 months after virological breakthrough. This patient had cirrhosis at baseline and a flare in ALT up to $3 \times$ ULN prior to hepatic decompensation. Despite receiving adefovir and achieving undetectable HBV DNA by PCR, he continued to deteriorate and received an orthotopic liver transplant 15 months after virological breakthrough. An additional four patients with GR had been started on adefovir, the remaining four patients remained stable and were evaluated for adefovir treatment. Three (33\%) of the nine patients with GR reverted to HBeAg positivity. In two patients, the reversion was transient, while the third patient remained HBeAg positive for 16 months. The third patient, who remained HBeAg positive, reverted from precore stop codon mutation to wild-type precore sequence. Reappearance of HBeAg was not observed in any of the patients who did not have GR, but reversion from precore stop codon mutation to wild-type precore sequence was observed in two of 41 (5\%) patients who did not have GR.

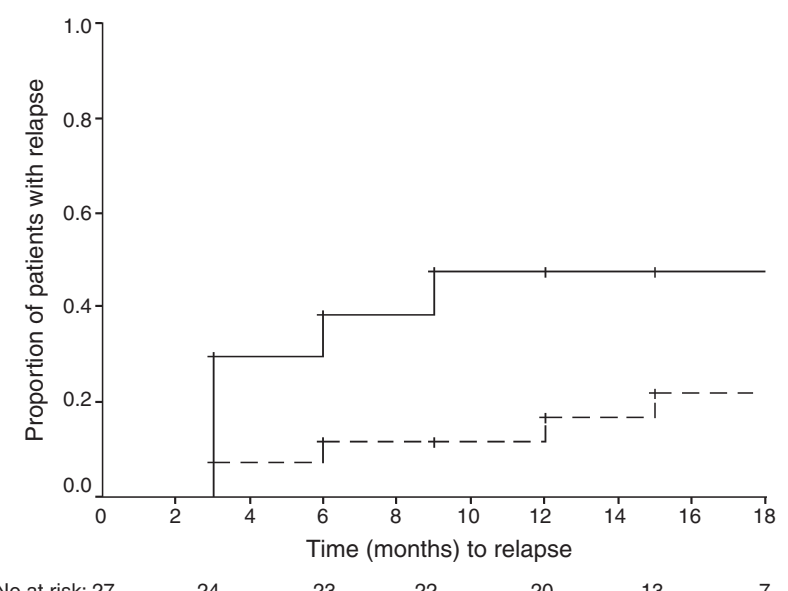

Fig. 4 Cumulative rates of virological (solid line) and clinical relapse (dashed line) after treatment withdrawal. Virological relapse was defined as reappearance of HBV DNA by PCR assay. Clinical relapse was defined as detection of HBV DNA by hybrid capture assay and ALT $>1.5 \times$ ULN.

\section{Treatment withdrawal and post-treatment relapse}

Twenty-seven of 37 (73\%) patients who completed 24 months lamivudine treatment fulfilled criteria for treatment withdrawal. Twenty-three $(85 \%)$ patients have been followed for a minimum of 6 months and 20 (74\%) patients for more than 12 months after treatment withdrawal. Twelve (44\%) patients had evidence of virological relapse, and seven (26\%) had clinical relapse. HBV DNA in those who experienced clinical relapse ranged from $1.4 \times 10^{6}$ to $5.6 \times 10^{8}$ copies $/ \mathrm{mL}$. The cumulative rates of clinical and virological relapse are illustrated in Fig. 4. The probability of clinical and virological relapse 6, 12 and 18 months after treatment withdrawal were $12 \%$ and $30 \%, 18 \%$ and $50 \%$, and 30 and $50 \%$, respectively. The median time to virological relapse was 4.5 months (range 3-9 months), while the median time to clinical relapse was 12 months (range 3-27 months). All patients with clinical relapse were men and six patients $(86 \%)$ were infected with HBV genotype $\mathrm{C}$ (see Table 2). Patients with clinical relapse have been followed for a median of 27 months (range 15-36 months) after treatment withdrawal and none of these patients has experienced an increase in total bilirubin or evidence of hepatic decompensation. All but one patient with clinical relapse have responded to re-treatment with lamivudine. The median duration of re-treatment was 15 months (range 3-33 months).

\section{DISCUSSION}

This is the first report of a 2-year course of lamivudine treatment in Asian patients with e-CHB. Although there is extensive literature on the efficacy of lamivudine treatment of patients with e-CHB in southern European countries, the 
Table 2 Comparison of patients with and without clinical relapse after treatment withdrawal

\begin{tabular}{|c|c|c|c|}
\hline & Clinical relapse & No clinical relapse & $P$ \\
\hline No. of patients & 7 & 20 & - \\
\hline Gender M:F & $7: 0$ & $15: 5$ & 0.34 \\
\hline Mean age in years \pm SD & $41.7 \pm 14.8$ & $44.9 \pm 8.9$ & 0.68 \\
\hline Genotype B:C & $1: 6$ & $3: 17$ & 0.98 \\
\hline Core promoter variant only (\%) & $5(71)$ & $9(45)$ & 0.31 \\
\hline Precore variant only $(\%)$ & $1(14)$ & $4(20)$ & 0.85 \\
\hline Double variants $(\%)$ & $1(14)$ & $6(30)$ & 0.57 \\
\hline Wild-type precore/core promoter sequence & $0(0)$ & $1(5)$ & 0.85 \\
\hline Median (range) pretreatment HBV DNA in $\log _{10}$ copies $/ \mathrm{mL}$ & $7.5(6.8-8.5)$ & $7.0(6.2-8.8)$ & 0.19 \\
\hline Median (range) pretreatment ALT/ULN & $2.6(1.5-11.9)$ & $2.1(1.4-7.3)$ & 0.34 \\
\hline Patients with pretreatment ALT > $>$ ULN $(\%)$ & $2(29)$ & $3(15)$ & 0.61 \\
\hline \multicolumn{4}{|l|}{ Liver histology } \\
\hline No. (\%) of patients with cirrhosis & $3(43)$ & $4(20)$ & 0.40 \\
\hline Median (range) inflammatory score $(\max =4)$ & $2(1-2)$ & $2(1-3)$ & 0.68 \\
\hline Median (range) fibrosis score $(\max =4)$ & $3(1-4)$ & $3(1-4)$ & 0.53 \\
\hline Median (range) ALT/ULN at month 24 & $0.95(0.4-1.1)$ & $0.55(0.2-1.4)$ & 0.43 \\
\hline Median (range) consolidation therapy in months* & $9(6-18)$ & $12(6-18)$ & 0.07 \\
\hline Median time to clinical relapse in months (range) & $12(3-27)$ & N/A & - \\
\hline Median follow-up post treatment in months (range) & $27(15-36)$ & $15(0-27)$ & 0.001 \\
\hline
\end{tabular}

*Duration of treatment from the time HBV DNA first became undetectable by PCR.

response to lamivudine therapy in Asian patients with e-CHB may be different because of differences in virological factors. Thus, while studies of Greek and Italian patients with e-CHB found that almost all patients had HBV genotype D and precore stop codon mutation, none of the patients in our study had genotype D and only 54\% had precore stop codon mutation.

Despite these differences, we demonstrated that lamivudine was effective in the treatment of e-CHB in Chinese patients. The initial response rate was comparable with or even better than that reported in other trials with $88 \%$ and $92 \%$ achieving undetectable HBV DNA by PCR and hybrid capture assay at month 12 compared with $60-70 \%$ in studies of European patients [16-20]. As seen in other studies, resistant mutants emerge with extended duration of treatment. Thus, at month 24 , virological response and biochemical response decreased to $74 \%$ and $66 \%$, respectively. Nine (18\%) patients developed GR before month 24 , with estimated cumulative rates of GR of $15 \%$ and $25 \%$ after 1 and 2 years of treatment, respectively. These rates of resistance appeared to be lower than that reported among European patients [18-20,22]. Additional studies with larger numbers of patients are needed to confirm if the rate of resistance to lamivudine in Chinese patients with e-CHB is indeed lower. Because of the small number of patients in this study, we were not able to identify factors associated with the development of GR.

Although the rate of GR was low, most (78\%) patients with GR had biochemical breakthrough. In addition, one patient with GR developed hepatic decompensation and ultimately required a liver transplant despite the addition of adefovir therapy. The high rate of biochemical relapse after virological breakthrough is similar to that observed among Greek patients [24]. In view of the potential adverse consequence of lamivudine resistance, it is important to determine if treatment withdrawal is possible in selected patients. Previous studies in European patients showed a high relapse rate when treatment was withdrawn in all patients after 12 months [16]. In our study, treatment was withdrawn only in patients who achieved undetectable HBV DNA by PCR on at least three occasions during the second year of treatment. Using these criteria, $73 \%$ of patients who completed 24 months of treatment were eligible for treatment withdrawal.

Despite the stringent criteria, a high rate of virological relapse $(50 \%$ had detectable serum HBV DNA by PCR assay at 18 months) was observed after treatment withdrawal. Virological relapse may precede clinical relapse. However, not all patients with virological relapse developed clinical relapse. The estimated rate of clinical relapse 18 months after treatment withdrawal was only $30 \%$. We used the same criteria for initial treatment as definition for clinical relapse because it is unclear if very low levels of HBV DNA detectable only by PCR assay are clinically significant and warrant re-treatment. We acknowledge that the duration of post-treatment follow-up is relatively short, and it is conceivable that with time, more patients may experience virological and ultimately clinical relapse. However, all episodes of virological relapse occurred within 12 months of treatment withdrawal while clinical relapse was delayed by 
6 months. As $74 \%$ of the patients had at least 12 months and $50 \%$ had at least 18 months of post-treatment followup, our data suggest that a sustained response can be achieved in selected patients with longer duration of treatment. Another limitation of our study is the lack of follow-up liver biopsies. Patients with virological relapse may experience progressive liver disease, even if the ALT remains below $1.5 \times$ ULN. Analysis of the clinical and laboratory parameters at baseline and month 24 found that all patients who relapsed were men with genotype $\mathrm{C}$. These findings, if confirmed, can be used to further refine the criteria for treatment withdrawal in future patients.

In summary, this report of lamivudine treatment of e-CHB in Chinese patients demonstrated some fundamental differences in viral factors between Chinese and European patients with e-CHB. Nevertheless, initial virological and biochemical responses were comparable or even better than those reported in studies from Europe. GR appeared to occur at a lower rate, but almost all patients with virological breakthrough developed biochemical breakthrough. Lamivudine may be safely withdrawn in selected patients, who achieve adequate viral suppression after 2 years of treatment. However, close follow-up after treatment withdrawal is required to detect clinical relapse. Although virological relapse was relatively common, not all patients developed clinical relapse. Longer follow-up of a larger number of patients is needed to confirm our findings, to identify factors that are predictive of relapse, and to further refine the criteria for lamivudine withdrawal in patients with e-CHB.

\section{REFERENCES}

1 Lok AS, Heathcote EJ, Hoofnagle JH. Management of Hepatitis B 2000, Summary of a Workshop. Gastroenterology 2001; 120: 1828-1853.

2 Brunetto MR, Oliveri F, Rocca G et al. Natural course and response to interferon of chronic hepatitis $\mathrm{B}$ accompanied by antibody to hepatitis B e antigen. Hepatology 1989; 10: 198-202.

3 Laras A, Koskinas J, Avgidis K, Hadziyannis SJ. Incidence and clinical significance of hepatitis B virus precore gene translation initiation mutations in e antigen-negative patients. J Viral Hepatitis 1998; 5: 241-248.

4 Naoumov NV, Schneider R, Grotzinger T et al. Precore mutant hepatitis B virus infection and liver disease. Gastroenterology 1992; 102: 538-543.

5 Grandjacques C, Pradat P, Stuyver L et al. Rapid detection of genotypes and mutations in the pre-core promoter and the pre-core region of hepatitis B virus genome: correlation with viral persistence and disease severity. J Hepatology 2000; 33 : 430-439.

6 Chu CM, Yeh CT, Chiu CT, Sheen IS, Liaw YF. Precore mutant of hepatitis $\mathrm{B}$ virus prevails in acute and chronic infections in an area in which hepatitis B is endemic. J Clin Microbiol 1996; 34: 1815-1818.

7 Carman WF, Jacyna MR, Hadziyannis S et al. Mutation preventing formation of hepatitis $\mathrm{B}$ e antigen in patients with chronic hepatitis B infection. Lancet 1989; 2: 588591.

8 Kramvis A, Kew MC, Bukofzer S. Hepatitis B virus precore mutants in serum and liver of South African blacks with hepatocellular carcinoma. J Hepatology 1998; 28: 132141.

9 Funk M, Rosenberg D, Lok A. Worldwide epidemiology of HBeAg-negative chronic hepatitis B and associated precore and core promoter variants. J Viral Hepatitis 2002; 9: 5261.

10 Chan HLY, Leung NWY, Hussain M, Wong ML, Lok ASF. Hepatitis B e antigen-negative chronic hepatitis B in Hong Kong. Hepatology 2000; 31: 763-768.

11 Okamoto H, Tsuda F, Akahane Y et al. Hepatitis B virus with mutations in the core promoter for an e antigen-negative phenotype in carriers with antibody to e antigen. J Virol 1994; 68: 8102-8110.

12 Lindh M, Andersson A, Gusdal A. Genotypes, nt 1858 variants, and geographic origin of hepatitis B virus - large scale analysis using a new genotyping method. J Infect Dis 1997; 175: 1285-1293.

13 Chu C, Hussain M, Lok A. Hepatitis B virus genotype B is associated with earlier spontaneous seroconversion than hepatitis B virus genotype C. Gastroenterology 2002; 122: 1756-1762.

14 Lai CL, Chien RN, Leung NW et al. A one year trial of lamivudine for chronic hepatitis B. Asia Hepatitis Lamivudine Study Group. N Eng J Med 1998; 339: 61-68.

15 Dienstag JL, Schiff ER, Wright TL et al. Lamivudine as Initial Treatment for Chronic Hepatitis B in the United States. N Engl J Med 1999; 341: 1256-1263.

16 Sanantonio T, Mazzola M, Iacovazzi T et al. Long term follow-up of patients with anti- HBe/HBV DNA-positive chronic hepatitis $\mathrm{B}$ treated for 12 months with lamivudine. J Hepatology 2000; 32: 300-306.

17 Buti M, Cotrina M, Jardi R et al. 2 years of continuous lamivudine in anti-HBe-positive patients with chronic hepatitis B. J Viral Hepatitis 2001; 8: 270-275.

18 Tassopoulos NC, Volpes R, Pastore G et al. Efficacy of lamivudine in chronic hepatitis B with hepatitis B e antigennegative/hepatitis B virus DNA-positive (precore mutant) chronic hepatitis B. Lamivudine Precore Mutant Study Group. Hepatology 1999; 29: 889-896.

19 Hadziyannis, SJ, Papatheodoridis GV, Dimou, E, Laras A, Papaioannou C. Efficacy of long-term lamivudine monotherapy in patients with hepatitis $\mathrm{B}$ e antigen-negative chronic hepatitis B. Hepatology 2000; 32:847-851.

20 Rizzetto M, Volpes R, Smedile A. Response of pre-core mutant chronic hepatitis B infection to lamivudine. J Med Virol 2000; 61: 398-400.

21 Tassopoulos NC, Volpes R, Pastore G et al. Post lamivudine treatment follow-up of patients with $\mathrm{HBeAg-negative} \mathrm{chro-}$ nic hepatitis B (abstract). J Hepatology 1999; 30(suppl 1):117.

22 Lok ASF, Hussain M, Cursano C et al. Evolution of hepatitis $\mathrm{B}$ virus polymerase gene mutations in hepatitis B e antigennegative patients receiving lamivudine therapy. Hepatology 2000; 32:1145-1153. 
23 Schalm SW, Heathcote J, Cianciara J et al. Lamivudine and alpha interferon combination treatment of patients with chronic hepatitis B infection: a randomised trial. Gut 2000; 46: $562-568$.

24 Papatheodoridis G, Dimou E, Laras A, Papadimitropoulos V, Hadziyannis S. Course of virologic breakthroughs under long-term lamivudine in $\mathrm{HBeAg-negative} \mathrm{precore} \mathrm{mutant}$ HBV liver disease. Hepatology 2002; 36: 219-226.
25 Bedossa P, Poynard T. for the METAVIR Cooperative Study Group. An algorithm for the grading of activity in chronic hepatitis C. Hepatology 1996; 24: 289-293.

26 Pawlotsky J. Molecular diagnosis of viral hepatitis. Gastroenterology 2002; 122: 1554-1568. 